\title{
Air and soil frost indices in relation to plant mortality in elevated clear-felled terrain in Central Sweden
}

\author{
L. Lindkvist ${ }^{1, *}$, D. Chen ${ }^{2}$ \\ ${ }^{1}$ C ounty Forestry Board of West G ötaland, Box 343, S-503 11 Borås, Sweden \\ ${ }^{2} \mathrm{G}$ öteborg University, Dept of Earth Sciences Centre, Lab of Climatology, G uldhedsgatan 5A, S-405 30 G öteborg, Sweden
}

\begin{abstract}
This study investigates the occurrence of low summer night temperatures in relation to plant mortality in a confined clear-felled area. The work was carried out in highly complex and elevated mountainous terrain in central Sweden. Indices for air and soil frost were developed to identify the relationship between low temperatures and plant mortality during the peak of the growing season. The indices are based on air temperature measurements at 29 stations and soil temperature measurements for 2 depths at 4 stations. The terrain was classified according to its curvature at each sampling site. Four main terrain types and 2 subtypes were identified, which allowed for an analysis that links the air frost index to a specific terrain feature. An inventory of plant mortality was carried out in circular areas of $500 \mathrm{~m}^{2}$ which were centred around the sampling sites. It was found that terrain curvature and aspect in relation to solar azimuth angle around sunrise and sunset have a significant impact on the frequency of low night temperatures in summer. This was also reflected by the distribution differences of surviving plants between various terrain types. The air frost index was highly correlated to the mortality ( $r=0.91, N=29$ ). However, an analysis of the residual in the regression indicates that other factors are also important. The soil frost index helps explain the relatively high mortality in convex terrain. Also, the influence of temperature-induced frost hardening on the mortality during the vegetative period is discussed.
\end{abstract}

KEY WORDS: High elevation · Complex terrain - Vegetative period · Plant mortality · Temperature indices · Air frost · Soil frost

\section{INTRODUCTION}

In the southern and central Swedish mountains (the Scandes), coniferous forests are situated at elevations ranging from approximately 600 to $900 \mathrm{~m}$ above sea level (Fig. 1), where summer night frosts are anticipated throughout the growing season. Low temperature is one of the most important natural limiting factors with regard to the survival, growth and distribution of plants. The variability of survival within populations of boreal coniferous plants is mainly a measure of the variability in resistance to stress from low temperatures both in the air and soil. Eiche (1966) found

*E-mail: lars.lindkvist@svsvg.svo.se that widespread cold damage in coniferous forests particularly affected afforestation and natural reproduction in upland areas of central and northern Sweden.

Part of the southern Swedish Scandes shows a topographical complexity that enables the development of regional temperature variations of considerable magnitude on a regular basis. The temperature distribution in relation to latitude and elevation in the southern and central Swedish Scandes is described in an early study by Ångström (1974). Various temperature indices relevant to the vegetation such as the length of the growing season, growth units, respiration equivalents, temperature sum, radiation cooling and frost risk have been estimated at a rather coarse regional scale to describe the bioclimate of the area (e.g. Perttu 1981, Odin et. al. 1983). We found, from measurements in 


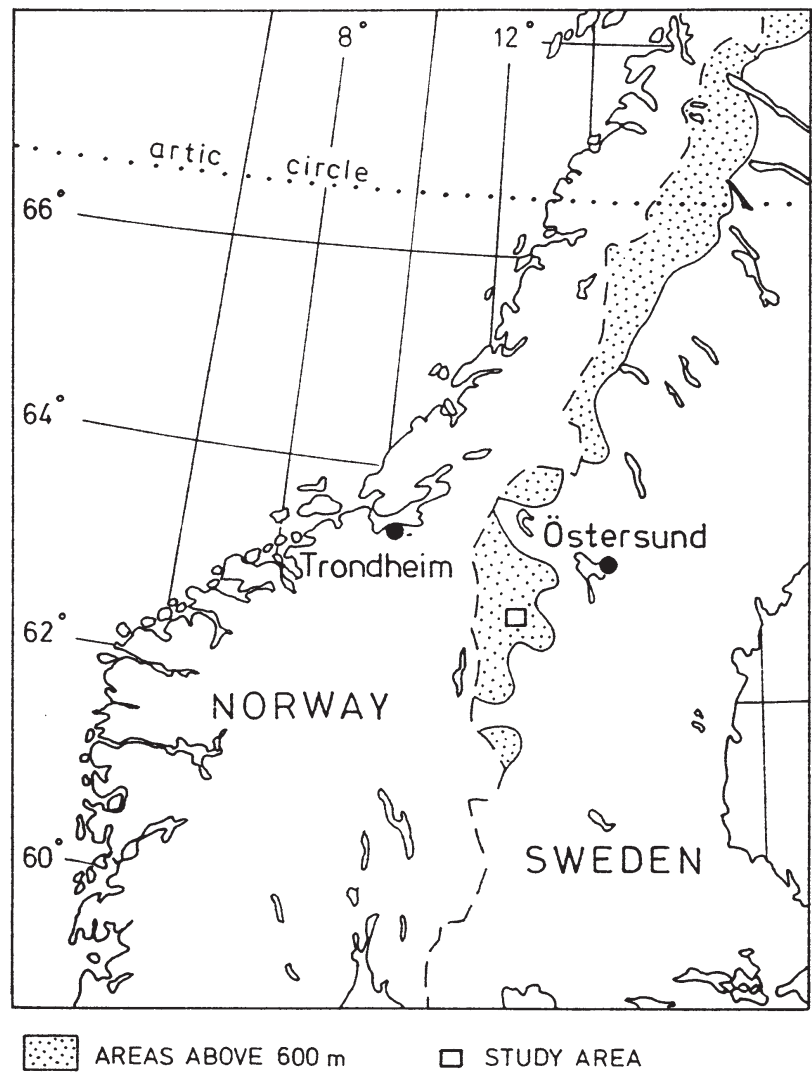

Fig. 1. Location of the study area in the southern part of the Scandinavian mountain range 'the Scandes'. Distribution of areas greater than $600 \mathrm{~m}$ above sea level is indicated

1995 and 1996, that the variations in the local summer temperature climate are of at least the same magnitude as the regional. However, this has rarely been investigated in detail along the Scandes. In terms of artificial and natural reproduction, it is important to find ways to characterise such variations in relation to their impact on plant growth and survival at both a local and regional scale.

Subzero summer night air temperatures occur regularly in the studied area and are likely to result in freezing of plant tissue. This phenomenon has been discussed by many authors as one of the most important factors regulating plant distribution and mortality in cold environments. Li \& Sakai (1981) and Sakai \& Larcher (1987) give extensive reviews on this subject.

Frost temperatures in soil during spring have also been identified as leading to stress caused by desiccation in plants and trees (Tranquillini 1979, Fuchinoue 1982). In a Norwegian study of spruce and pine, Venn \& Solheim (1990) reported that injury to and death of trees were similar in appearance to that caused by drought. A closer examination revealed that the roots were exposed to temperatures below zero for a length of time after growth had likely commenced. Extensive damage of a similar type has also been reported in Sweden (Kullman \& Högberg 1987).

The ability to resist low temperatures both in the air and soil is generally termed 'plant acclimatisation' or 'plant cold hardiness'. It is usually rated according to the lowest average minimum temperature during the quiescent period (winter) at which a woody species can survive (Kalma et al. 1992). However, the tolerance to freezing is more relevant to the vegetative period in areas where repeated frosts are anticipated during the active growth phase and this necessitates the study of summer frost intensity. Experimental studies, both in the field and in the more controlled laboratory environments, have shown that critical threshold temperatures in non-hardened conifer tissue indicate the following: tissue death occurs at temperatures of -2 to $-3^{\circ} \mathrm{C}$ (Burke et al. 1976, A ronsson 1979); extra-cellular freezing commences at temperatures of $-2^{\circ} \mathrm{C}$ (Asahina 1956, Weiser 1970); and the occurrence of plant mortality is in the range of -3 to $-4^{\circ} \mathrm{C}$ (Bergman 1968, Christersson 1971). The temperature intervals related to freezing and plant injury are quite consistent in the different studies. In addition, the degree of injury and rate of mortality follow, to a certain extent, fixed temperature steps.

A locally complex terrain is likely to produce spatial variations in the temperature distribution. The aim of this work is to define terrain features that facilitate the development of summer frosts that correspond to an expected range of plant mortality. Specifically, the following 2 indices are developed to study the relationship between the distribution of low temperatures and plant mortality: (1) a local summer frost index $\left(I_{a}\right)$, which specifies a weighted intensity and frequency of air frost temperatures in 6 pre-defined terrain forms; and (2) a relative desiccation index $\left(\mathrm{l}_{\mathrm{s}}\right)$, which specifies the accumulated time (hours) of soil frost when the near-surface air temperature is above freezing in 4 pre-defined terrain forms.

\section{LOW TEM PERATURE STRESS AND PLANT PHYSIOLOGY - A BACKGROUND}

During the active phase of growth, the plant will respond to low temperatures principally in 2 ways, extra-cellular and intra-cellular freezing. The degree of cold, the period of exposure and the rate of temperature change are factors that determine the extent and type of impact that will take place in the plant tissue. Extra-cellular freezing is defined as ice formation on the surface of the cell, which dehydrates the cell due to the lower vapour pressure over the crystallised water. Intra-cellular freezing occurs spontaneously at temper- 
atures of around $-10^{\circ} \mathrm{C}$ in non-hardened conifer vegetation (Mazur 1977), and this usually kills the cells instantly due to the fast growth of ice crystals, which penetrate the cell wall. However, many intermediate forms of injury take place and not all forms of freezing are lethal, i.e. a plant, weakened by low temperatures, becomes susceptible to other forms of stress that could also lead to death.

To manage the different freezing processes the plant must adapt to low temperature. Burke et al. (1976) used the term 'acclimation' to express the seasonal transition from the tender to the hardy condition in hardy species. Weiser (1970) identified 3 different stages of acclimation of plants to low temperatures. Growth cessation, which

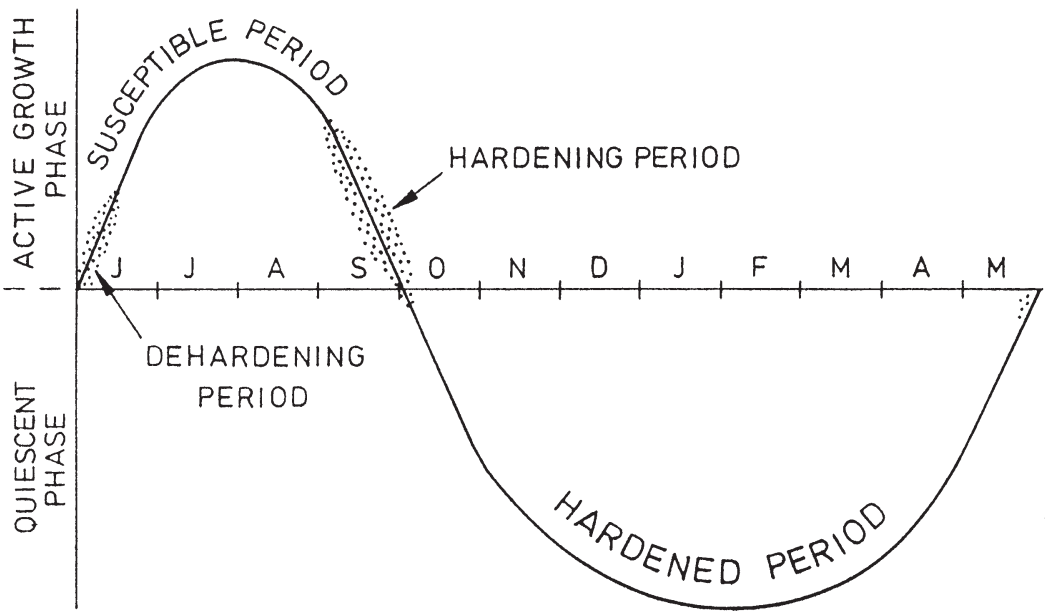

Fig. 2. A schematic presentation of the interaction between the annual variation in climate and the physiological phases for boreal needle vegetation. The different phases have been adjusted to the cold-climate conditions at the study site (>600 $\mathrm{m}$ above sea level) in the central Swedish mountains hardening period, is also identified as an important mechanism that prevents frost injury. N orthern plants cease to grow earlier in autumn and if seeds from such plants are transferred south, they will keep their specific endogenous growth rhythm (Galston et al. 1980). The plants thereby manage the early autumn frost better than the local vegetation. Furthermore, the type of injury and the mechanisms of acclimation to low temperature vary depending on species. Thus, cold damage as a phenomenon associated with hardening and other acclimation processes becomes an intricate problem.

The interaction between the annual variation in climate and the annual physiological phases of boreal needle vegetation is schematically shown in Fig. 2 . The approximate periods, relevant to the investigated region, of dehardening, active growth, hardening and rest are indicated. The beginning of the growing season during the period 1994-1996 varied for the study area between May 26 and J une 4, while the ending of this season ranged between September 16 and 22 . Odin et al. (1983) defined the growing season with the following: a daily mean temperature of $+5^{\circ} \mathrm{C}$ or above for $4 \mathrm{~d}$ marks the start of this season and, accordingly, temperatures below $+5^{\circ} \mathrm{C}$ indicate the cessation.

\section{MATERIAL AND METHODS}

3.1. Site description. The study region is located in the southern Scandinavian mountain range at $62^{\circ} 38^{\prime} \mathrm{N}, 13^{\circ} 00^{\prime} \mathrm{E}$ (Fig. 1). The elevation of the area varies between 600 and $1400 \mathrm{~m}$ above sea level and the transitions between high and low areas are sharp, often with slope inclinations of 10 to $20 \%$. The climate is characterised as a mountainous local maritime climate in the northern region and an elevated local continental climate in the south (Ångström 1974).

The region contains a characteristic type of terrain that is of specific interest to this study. Moraine deposits, glaciofluvial remnants and bedrock features make up a sharply undulating local topography where the various terrain features have a relative difference of 5 to $15 \mathrm{~m}$ in height, i.e. 'basin and knob' terrain. Such variations in the terrain give different conditions for climate related processes, such as ground heating by solar radiation, mixing of near-ground air, and cold air drainage. The variations in the local terrain also lead to differences in accumulation of snow, soil water content and ground vegetation cover. In turn, this causes variation in the soil heat fluxes and the emissivity and albedo of the surface. All these factors are of importance in the context of the establishment of low temperatures and frosts in both the air and the soil.

Summer frosts occur approximately 5 times more often in lower concave basins than on elevated knobs, with variations in night temperature of 5 to $10^{\circ} \mathrm{C}$ being common during the growing season. The study area, which is located at $740 \mathrm{~m}$ above sea level, is an example of the described terrain (Fig. 3). This area was clear-felled in 1987 and planted $2 \mathrm{yr}$ later with $1 \mathrm{yr}$ old saplings of Picea abies and Pinus contorta, of a local provenance. The planting was carried out with a density of 2200 saplings ha- ${ }^{-1}$.

3.2. Data acquisition. Hourly values of air temperature during the 1994 and 1995 growing seasons were measured at 29 locations at $30 \mathrm{~cm}$ above ground level, corresponding to the mean height of the coniferous 


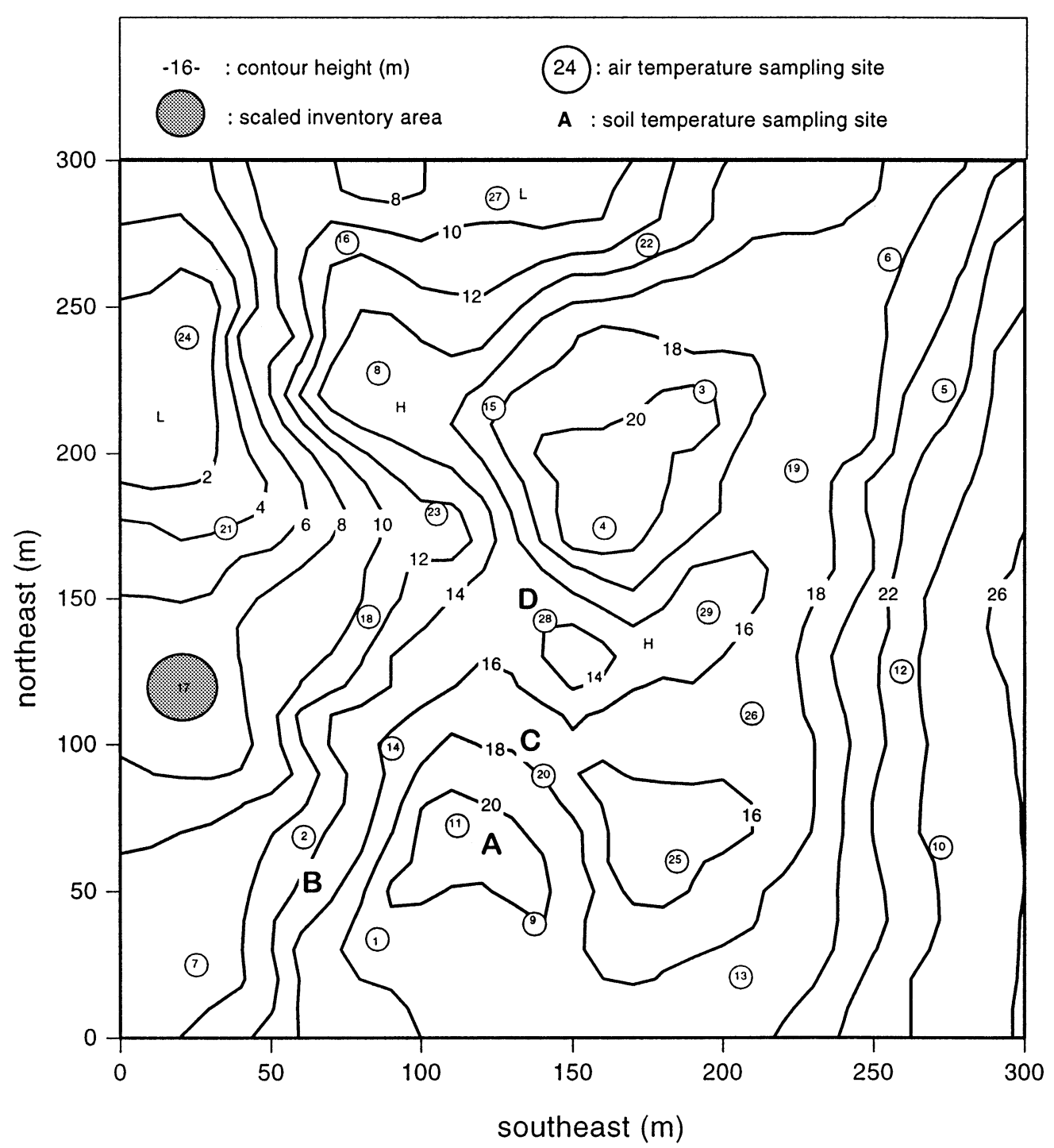

Fig. 3. Map of the investigated area depicting contour lines at $1 \mathrm{~m}$ intervals. The air temperature sampling sites are marked and numbered according to increased air frost index values (see Table 1). Large grey circle: relative size of the circle areas used for an inventory of plant mortality. $\mathrm{H}$ and L: position is higher or lower than the nearest contour line without reaching the next contour value

saplings. One-channel data loggers with built-in thermistors (Orion Components, Chichester Ltd) stored the temperature information. The sensors have an accuracy of $0.2^{\circ} \mathrm{C}$ in the range +10 to $-12^{\circ} \mathrm{C}$. The measuring system has a time constant of 8 to $10 \mathrm{~min}$ when stored in a small case of aluminium and placed in the centre of an unventilated radiation shield. Soil temperatures at 3 and $10 \mathrm{~cm}$ below the surface and air temperatures at $30 \mathrm{~cm}$ were measured in vertical profiles at 4 locations. Each location has a specific terrain form with various degrees of wind shelter and solar radiation screening. Thin platinum sensors (Pt100, accuracy $0.1^{\circ} \mathrm{C}$ ) and a Campbell Scientific Inc. CR10 data logger were used for this purpose. The sensors were placed in the ground after the soil was frozen in order to minimise dislocation due to frost heave. In addition, the wind speed and wind direction were continuously sampled over the $2 \mathrm{yr}$ and the snow depths in various terrain forms were monitored every second month within the area during the winter and spring of 1994-1995.

Air temperatures were measured at sites representative of a set of pre-determined terrain elements. Each element constitutes a simple form of terrain curvature that, in various combinations, is able to represent a higher degree of terrain complexity. Basically, 4 types of curvature were identified: (1) linear sloping curvature, (2) linear flat curvature, (3) convex curvature and 
(4) concave curvature. Since variation in aspect and position results in differences for time of shadow between specific sites, both sloping and flat curvature were further divided into non-screened and screened areas, the latter are shaded during the afternoon and/or morning hours. The screened flat areas are defined in an analogous way. The convex forms are always considered to be non-screened due to their shape and position relative to their surroundings. In contrast, concave terrain is always considered to be screened, for the same reason. In this way 6 terrain elements were defined and are symbolically presented in Table 1.

An inventory of planted coniferous saplings was carried out in 1994 and 1996. Information on the initial plant numbers, supplied by the National Board of Forestry, facilitated the calculations of 5 and $7 \mathrm{yr}$ mortality rates. A simple inventory method was applied, whereupon a plant count was undertaken in circular areas centred on each of the temperature sampling sites. It is essential that the inventory and the temperature samplings cover a similar spatial range in order to correlate the terrain curvature to a specific rate of mortality and frost intensity.

In this context, spectral analysis of spatial data is a useful tool for identifying the characteristics of a complex terrain since it gives the dominant length-scale of the terrain. Therefore, the relative elevation in the investigated area was surveyed at nearly 400 points with a Leica TS 4000 survey instrument. The spectral analysis defined the 2 most significant lengths to be where distinct peaks at distances of around 25 to $30 \mathrm{~m}$ were identified. The distance range corresponds to an approximate size of distinct terrain forms such as knobs, ridges and concavities that characterise the topography of the investigated region. Based on these

Table 1. Summer air frost index values $\left(I_{a}\right)$ and plant mortality in relation to 6 pre-defined terrain forms at the sites in the central Swedish mountains. The subscript 'ss' indicates terrain forms that are wind sheltered and screened from solar radiation at the time of sunrise and/or sunset. The directions in which the slope terrains face are given. Site numbers correspond to those in Fig. 3. The temperature intervals for the different index values are given

\begin{tabular}{|c|c|c|c|c|c|c|c|c|c|}
\hline \multirow[t]{2}{*}{ Site } & \multicolumn{6}{|c|}{ - Terrain curvature } & \multirow{2}{*}{$\mathrm{I}_{\mathrm{a}}$} & \multirow{2}{*}{$\begin{array}{c}\text { Mortality } \\
(\%)\end{array}$} & \multirow{2}{*}{$\begin{array}{c}\text { Temp. } \\
\text { interval }(\mathrm{i}) \\
\left({ }^{\circ} \mathrm{C}\right)\end{array}$} \\
\hline & Convex & $\begin{array}{c}\downarrow \\
\text { Slope }\end{array}$ & $\stackrel{\leftrightarrow}{\text { Flat }}$ & $\begin{array}{c}\Downarrow \\
\text { Slope }_{\text {ss }}\end{array}$ & $\begin{array}{c}\Leftrightarrow \\
\text { Flat }_{\mathrm{sS}}\end{array}$ & $\stackrel{\cup}{\text { Concave }}$ & & & \\
\hline 1 & $x$ & & & & & & 4 & 11 & -2.5 to \\
\hline 2 & & NW & & & & & 5 & 14 & -4.3 \\
\hline 3 & $x$ & & & & & & 5 & 9 & $\downarrow$ \\
\hline 4 & $\times$ & & & & & & 5 & 25 & \\
\hline 5 & & NW & & & & & 5 & 2 & \\
\hline 6 & & & $x$ & & & & 6 & 19 & \\
\hline 7 & & & $x$ & & & & 7 & 18 & \\
\hline 8 & $x$ & & & & & & 7 & 36 & \\
\hline 9 & $x$ & & & & & & 7 & 38 & \\
\hline 10 & & NW & & & & & 8 & 5 & \\
\hline 11 & & & $x$ & & & & 9 & 32 & \\
\hline 12 & & NW & & & & & 10 & 11 & \\
\hline 13 & & & $x$ & & & & 11 & 27 & \\
\hline 14 & & NW & & & & & 11 & 36 & \\
\hline 15 & & NW & & & & & 11 & 22 & \\
\hline 16 & & & & NE & & & 19 & 38 & 4.4 to \\
\hline 17 & & & & & $x$ & & 21 & 43 & -6.2 \\
\hline 18 & & & & $\mathrm{~N}$ & & & 23 & 53 & $\downarrow$ \\
\hline 19 & & & & & $x$ & & 27 & 57 & \\
\hline 20 & & & & $E$ & & & 28 & 68 & \\
\hline 21 & & & & $\mathrm{~N}$ & & & 32 & 72 & \\
\hline 22 & & & & $\mathrm{~N}$ & & & 34 & 66 & \\
\hline 23 & & & & & & $x^{a}$ & 34 & 49 & \\
\hline 24 & & & & & & $\hat{x^{a}}$ & 35 & 54 & \\
\hline 25 & & & & & & $x$ & 45 & 56 & -6.3 to \\
\hline 26 & & & & & $x^{b}$ & & 47 & 68 & -8.1 \\
\hline 27 & & & & & & $x$ & 56 & 68 & $\downarrow$ \\
\hline 28 & & & & & & $x^{b}$ & 78 & 74 & 8.2 to \\
\hline 29 & & & & & & $\widehat{x^{b}}$ & 83 & 82 & -10.0 \\
\hline
\end{tabular}


results an inventory circle with a diameter of $25.2 \mathrm{~m}$ $\left(500 \mathrm{~m}^{2}\right)$ was chosen, which is indicated at Site 17 in Fig. 3.

3.3. Concept and structure of an air frost index applicable to cold-climate forests. Any plant at a fixed location has a certain degree of susceptibility to injury by low temperatures. This can be described by factors such as the number of frost occasions, number of frost hours and the range of frost temperatures. In this study a combination of these variables are compiled into a number that constitutes a frost index. Essentially the purpose of this number is to capture the variability of summer frost intensity with relevance to the range of plant mortality that is observed in elevated complex terrain.

Our index incorporates temperature data from J uly and August. By restricting the index to this period, adaptations to low temperatures at the beginning and end of the growing season are avoided, as discussed in Section 2. It is established that a range of temperatures from -2 to $-4^{\circ} \mathrm{C}$ is required to obtain a frost intensity that can lead to injury and eventually death of tissue in non-hardened plants (e.g. Weiser 1970, Sakai \& Larcher 1987). Therefore, the index includes only frost occasions of $-3^{\circ} \mathrm{C}$ or below, which implies that each occasion accounted for is likely to cause damage to coniferous vegetation to an extent that is clearly observable.

The processing of temperature data into a frost index $\left(I_{a}\right)$ is carried out according to

$$
\mathrm{I}_{\mathrm{a}}=\sum_{\mathrm{i}=1}^{\mathrm{n}} \lambda_{\mathrm{i}} \alpha_{\mathrm{i}}
$$

where $\alpha_{i}$ is the frequency of hourly frost observations in the temperature interval $i$, which is assigned the weight $\lambda_{i}$, and $n$ is the number of intervals. The standard deviation of the measured temperatures defines the width of the intervals. Calculations of the standard deviation are made for data that is associated with frost occasions below $-3^{\circ} \mathrm{C}$. Thus the number of intervals used in the index is dependent on the range of temperature variations that occur.

The choice of weights is based on other related experimental studies of temperature-induced injury and plant mortality (e.g. Bergman 1968, Weiser 1970, Christersson 1971, Burke et al. 1976, Sakai \& Larcher 1987). Special attention is given to the investigation conducted by Bergman (1968), since it is relevant to the present study in that the type of species and the temperature intervals used during the freezing experiments are the same. The weight $\lambda_{\mathrm{i}}$ assigned to a particular temperature interval is such that $\lambda_{\mathrm{i}}=\mathrm{i}-1(\mathrm{i}=2$, n) while $\lambda_{i}=0.5$ because the first interval is for air temperatures between 0 and $-3^{\circ} \mathrm{C}$, a range unlikely to cause serious damage to plant tissue.

\section{RESULTS AND DISCUSSION}

\subsection{Distribution of air frost index values}

It is assumed that the curvature and relative position of the terrain elements are correlated to frost intensity, therefore a set of terrain forms was defined in Section 3.2. Temperature observation sites were distributed amongst these terrain forms as shown in Table 1 and Fig. 3. Terrain forms that are expected to yield extreme temperature values were included in order to determine a general approximate range of the index for Swedish mountain conditions.

The terrain form and the associated index value obtained at each of the measuring sites are given in Table 1. Table 1 also lists the temperature intervals obtained using a calculated standard deviation of $1.8^{\circ} \mathrm{C}$. The index compiled in this study contains values between 4 and 83. Three clear transitions characterise the distribution of values. The first is associated with frost occurring in the second temperature interval $\left(-4.4\right.$ to $\left.-6.2^{\circ} \mathrm{C}\right)$. Frost in this interval occurs mainly in flat or sloping terrain that is effectively screened from the incoming radiation during the evening and/or morning hours. A second transition is connected to locations that are exposed to temperatures in the third interval $\left(-6.3\right.$ to $\left.-8.1^{\circ} \mathrm{C}\right)$. Such sites are typically of screened flat or concave form. It appears that even small sheltered basins are efficiently screened from the incoming solar radiation and suppress the mixing of near-surface air. In a study in the same area carried out by Lindkvist \& Lindqvist (1997), it was found that differences in the cooling and warming rate of 3 to $6^{\circ} \mathrm{C} \mathrm{h}^{-1}$ were maintained at mean wind speeds of $1.5 \mathrm{~m} \mathrm{~s}^{-1}$ between basins and exposed knobs.

The third transition that occurs in the range of index values isolates a few extreme locations. These are Sites 28 and 29 (Fig. 3). Site 29 is of a distinct concave form and is situated in the middle of a large converging basin. Site 28 is similar but located on the upper edge of a depression. Both sites are screened from solar radiation during the afternoon and morning and the turbulence caused by light winds is significantly reduced. Their relative positions also make them liable for the receipt of cold air by drainage.

To characterise a temperature environment that is in clear contrast to Sites 28 and 29, Site 4 is chosen. This elevated knob is highly exposed to both incoming radiation and wind and considerable accumulation of cold air is not possible. Only 1 frost occurred at this site, which had a minimum temperature of $-3.2^{\circ} \mathrm{C}$. This is in contrast to the nearby basin that showed temperatures below $-9^{\circ} \mathrm{C}$ on several occasions. The 2 areas thus constitute extremely different environmental conditions with respect to the survival and growth of vegetation, yet they are located less than $50 \mathrm{~m}$ apart. 

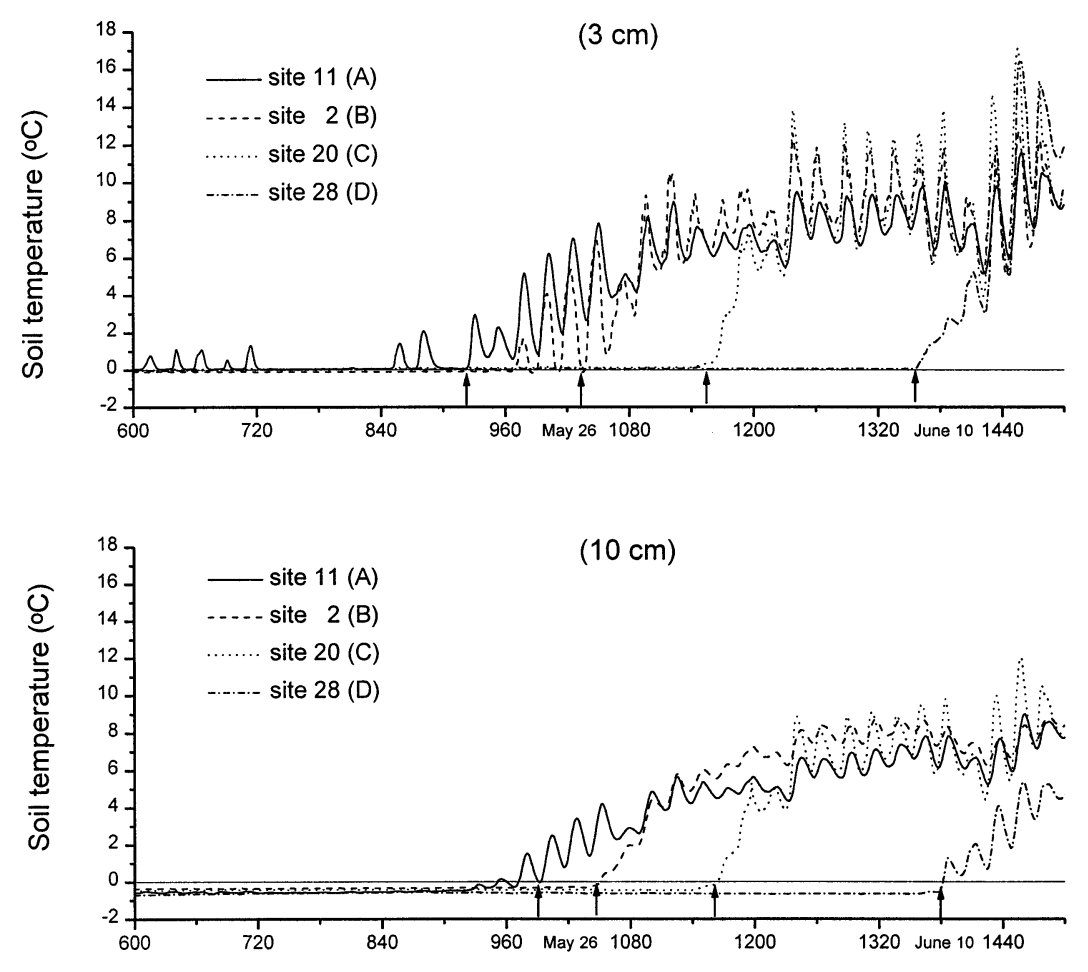

Hours elapsed after 0:00 on 14 April, 1995

Fig. 4. Relative time of defrosting (arrows) in the soil at 3 and $10 \mathrm{~cm}$ at the 4 Sites A to $D$

\subsection{Soil frost and plant desiccation}

Temperature variations in soil are important for plant survival and growth. This is especially true at the early stages of the growth. From the survival point of view, temperatures during frost periods are critical. Fig. 4 shows measured soil temperatures at 4 locations for 2 depths. Conditions for frost disappearance are quite different for the 4 locations. Site $A$ is the first to experience a temperature increase, which subsequently breaks through the frost conditions. Later Sites B, C and $\mathrm{D}$ also experience temperature increases.

This difference to a large extent is due to variations in snow depth. The presence of snow on the ground provides insulation from the surrounding air temperatures. It prevents penetration of low temperatures into the soil during winter and it counteracts the defrosting of the ground in spring. The wind and terrain conditions influence the local distribution of snow. Westerly winds of intermediate speed ( 3 to $6 \mathrm{~m} \mathrm{~s}^{-1}$ ) occur in the study area during winter, and wind gusts of 10 to $12 \mathrm{~m}$ $\mathrm{s}^{-1}$ are observed occasionally, mainly from the north and north-west. In 1995 this resulted in a snow distribution in which wind sheltered slopes and basins accumulated 4 to 7 times more snow than convex knobs. The results are given in Table 2 .
As winter proceeds, the difference in snow distribution is intensified. Accumulated snow is compressed and layers of different snow density are formed, which slows the rate of snowmelt. Thus patches of compacted snow and ice continue to remain after the start of the growing season in concave terrain and wind sheltered areas.

The accumulation of snow and the following snow-melt was monitored in different types of terrain in order to study the influence that this process has on the time of defrosting in the soil (Tables $2 \& 3$ ). The timing of defrosting in soil is an important factor, as it determines the beginning of many biological activities. We define defrosting as the time of commencement of temperatures that are continuously above zero for at least $2 \mathrm{~d}$. These commencement times at the 4 locations are marked with arrows in Fig. 4. Table $3 a$ shows the timings and the differences between the 2 depths. To determine the differences between the 4 locations qualitatively, the defrosting times relative to that of Site $A$ were calculated (Table 3b).

The delay time between the defrosting at 3 and $10 \mathrm{~cm}$ is generally short ( 1 to $3 \mathrm{~d}$ ), which indicates that the defrosting at root level for young saplings (10 to $15 \mathrm{~cm}$ depth) is similar to that occurring near the surface $(3 \mathrm{~cm})$. This is consequently correlated to the time of completed snowmelt.

Depending on the soil depth considered, the defrosting at the concave site (D) is delayed by approximately 16 to $18 d$ relative to the convex location (A). A delay of 7 to $9 \mathrm{~d}$ is observed for the shaded and wind sheltered lower slope/flat area (C). The defrosting at the exposed slope (B) is shifted by approximately 3 to $5 \mathrm{~d}$ compared to that of the convex site.

Table 2. Differences in snow depth $(\mathrm{cm})$ throughout the year (1994-1995) for various terrain forms relative to that of convex terrain. The values are means of approximately 10 observations for each terrain form. Actual snow depths in concave areas are given in parentheses

\begin{tabular}{|lrrrrrr|}
\hline & $\cap$ & $\downarrow$ & $\leftrightarrow$ & $\Downarrow$ & $\Leftrightarrow$ & $\cup$ \\
\hline Dec & $0(24)$ & 4 & 8 & 17 & 21 & 32 \\
Feb & $0(31)$ & 16 & 11 & 37 & 30 & 64 \\
A pr & $0(20)$ & 35 & 29 & 90 & 76 & 145 \\
J un & $0(0)$ & 0 & 0 & 14 & 11 & 59 \\
& & & & & & \\
\hline
\end{tabular}


Table 3. (a) Defrosting dates for the 4 selected sites at 2 depths. Delay: difference in days between 10 and $3 \mathrm{~cm}$. (b) Defrosting times at 2 depths relative to that of Site A (in days)

\begin{tabular}{|c|c|c|c|c|}
\hline & $A \cap$ & $\mathrm{B} \downarrow$ & $C \Downarrow$ & $D \cup$ \\
\hline \multicolumn{5}{|c|}{ (a) Defrosting dates } \\
\hline $3 \mathrm{~cm}$ & May 22 & May 27 & J un 1 & J un 10 \\
\hline $10 \mathrm{~cm}$ & May 25 & May 28 & Jun 2 & Jun 11 \\
\hline Delay & 3 & 1 & 1 & 1 \\
\hline \multicolumn{5}{|c|}{ (b) Relative timing of defrosting } \\
\hline $3 \mathrm{~cm}$ & 0 & 4.6 & 9 & 18 \\
\hline $10 \mathrm{~cm}$ & 0 & 2.6 & 7 & 16 \\
\hline
\end{tabular}

Table 4. Accumulated negative temperature (ANT) $\left({ }^{\circ} \mathrm{C}\right)$ and number of occasions ( $\mathrm{N}$ ) when air temperatures are above and soil temperatures are below $0^{\circ} \mathrm{C}$ for the 4 selected sites

\begin{tabular}{|lcccc|}
\hline & $\mathrm{A} \cap$ & $\mathrm{B} \downarrow$ & $\mathrm{C} \Downarrow$ & $\mathrm{D} \cup$ \\
\hline $\mathrm{ANT}$ & -121.1 & -34.6 & -17.0 & -26.9 \\
$\mathrm{~N}$ & 312 & 166 & 99 & 103 \\
\hline
\end{tabular}

Once defrosting of the soil has commenced, dehardening of plant roots will follow. Nocturnal soil frost is common at a superficial level, particularly at locations where thawing is completed relatively early in the season. During this time plant roots are highly susceptible to freezing.

Large daily temperature variations are closely linked to plant stress due to frost desiccation. It is well known that frost desiccation threatens many plants in winter (Tranquillini 1979). This may be of more importance during spring when plants start to assimilate while soil temperatures are still below freezing. This relates to the fact that changes in climate conditions during spring trigger the plant to commence its physiological activities, which include assimilation, while plants in elevated areas are still under frost stress. The stomata open during assimilation and water vapour is lost. Thus, a situation where the soil water surrounding the root system is frozen and stomata are open during the day may lead to serious desiccation, particularly when the cell water content is low due to frost from the previous night, as discussed in Section 2. This is pointed out by Fuchinoue (1982), who arrived at the conclusion that events of extra-cellular freezing in leaf tissue cause severe desiccation damage after thawing, since the moisture in the inter-cellular space is likely to be lost by rapid transpiration.

The thermal inertia of the soil leads to phase shifts between the soil and air temperature. Here, the combination when the air temperatures are above $0^{\circ} \mathrm{C}$ while soil temperatures are still below $0^{\circ} \mathrm{C}$ is considered. In this context the number of occasions of such a combi- nation $(\mathrm{N})$ and the accumulated negative temperatures in the soil (ANT) calculated from the mean of the soil temperatures at 3 and $10 \mathrm{~cm}$ are certainly of interest.

Table 4 indicates the relative risk of desiccation as high and intermediate for convex terrain (A) and exposed slopes (B) respectively. It further indicates low desiccation risk for screened flat areas and concave terrain ( $C$ and $D$ ). It appears from the snow distribution (Table 2) and N (Table 4) that convex terrain, exposed slopes and el evated flat areas are likely to be subjected to frost desiccation more frequently than other terrain forms, in both winter and spring. Occasions during spring, according to Tranquillini (1979), are those which affect plant survival most seriously due to increased transpiration rates and water losses.

Sites $C$ and $D$ show approximately the same number of occasions but differ in accumulated negative temperatures, indicating that Site $D$ is subjected to more intense frost temperatures. However, it is unlikely that the impact of desiccation on plant survival is greater at this location, since desiccation is determined more by time rather than by intensity of frost. Fuchinoue (1982) suggested a similar interpretation; he showed that the accumulated time under which soil frost conditions prevail (for air temperatures above zero) is a crucial factor when determining the risk of plant desiccation. Fuchinoue also suggested that soil temperatures in the range 0 to $+5^{\circ} \mathrm{C}$ will lower the ability of roots to absorb water effectively and that the plant damage due to low temperatures in soil is severer than that due to a decrease in soil moisture. This statement appears reasonable for our study since the lowering of soil moisture is a rather slow process compared to the daily variations in soil temperature that are experienced in the investigated area (Fig. 4).

\subsection{Plant mortality}

The plant inventory shows highly variable rates of mortality in the pre-defined terrain forms of the study area. The mortality varies not only between areas of different terrain curvature but also within the same terrain forms. This is particularly obvious at slopes and flat areas, depending on their position relative to the surrounding terrain. Thus, it is assumed that the distribution is associated with the degree of shade and wind shelter that a specific terrain element is subjected to. An inventory of this kind should be carefully evaluated knowing that re-planting is carried out by hand and small variations in plant density should be expected. However, such variations are reduced due to the use of numerous and large inventory areas in this study.

The range of plant mortality in relation to the different terrain forms is given in Table 1 . In this context a 
relevant observation is the highly varied mortality that exists at slopes of different aspect and elevation and in flat areas of different elevation. Cold air accumulation on low flat ground, which extends to the lower parts of surrounding slopes, provides an explanation for the differences in mortality rates in these terrain forms. For example, on slopes very high rates are found at Sites 20, 21 and 22 as compared to the intermediate mortality found at Sites 14, 16 and 18 and the quite low rates at Sites 5, 10 and 12 (Fig. 3, Table 1). These sites represent a gradual change from shaded to exposed topography in relation to afternoon and evening incoming radiation.

The average proportion of missing plants in the area is $40 \%$. Similar results have been obtained from field investigations in Sweden for fields planted with both local and transferred saplings (Eiche 1966, Bergman 1968). The chance for survival of Norwegian spruce is normally improved by transferring plants of a northern provenance towards the south. According to Persson \& Ståhl (1990), the absence of such improvements is probably due to the relatively high altitude of the central Swedish mountains, resulting in a low yearly temperature sum (below $700^{\circ} \mathrm{C}$ ). The study area is above $700 \mathrm{~m}$ and the mean temperature sum is $560^{\circ} \mathrm{C}$ for the period 1994-1996. The study by Bergman (1968) was carried out as a controlled survival test, using specific frost temperature levels with exposure times of 1 and $3 \mathrm{~h}$ at each level. Table $5 \mathrm{com}$ pares the findings of the present study with the results obtained by Bergman.

The comparison suggests that the major portion of plant death takes place at an early stage of development since the rate of mortality after 1 summer is similar to the rate observed in the $5 \mathrm{yr}$ range. It is noticed that the increase in missing plants between 5 and $7 \mathrm{yr}$ is less than $2 \%$, which also suggests that the early

Table 5. Comparison between a mortality study over 1 summer using fixed frost levels (Bergman 1968) and the present field inventory of mortality rates at various temperature intervals 5 and $7 \mathrm{yr}$ after re-planting. Both studies used pine and spruce saplings originating from the same latitude $\left(63^{\circ} \mathrm{N}\right)$

\begin{tabular}{|c|c|c|c|c|}
\hline \multicolumn{2}{|c|}{ Bergman (1968) } & \multicolumn{3}{|c|}{ Present study } \\
\hline \multirow{2}{*}{$\begin{array}{l}\text { Frost in- } \\
\text { tensity }\left({ }^{\circ} \mathrm{C}\right)\end{array}$} & \multirow{2}{*}{$\begin{array}{c}\text { Mortality } \\
(\%)\end{array}$} & \multirow{2}{*}{$\begin{array}{l}\text { Frost in- } \\
\text { tensity }\left({ }^{\circ} \mathrm{C}\right)\end{array}$} & \multicolumn{2}{|c|}{ M ortality (\%) } \\
\hline & & & $5 \mathrm{yr}$ & $7 \mathrm{yr}$ \\
\hline-3 & 14.0 & -2.5 to -4.3 & 18.3 & 18.3 \\
\hline-5 & 43.0 & -4.4 to -6.2 & 55.6 & 57.0 \\
\hline-7 & 63.8 & -6.3 to -8.1 & 64.0 & 64.0 \\
\hline-9 & 69.2 & -8.1 to -10.0 & 78.0 & 78.6 \\
\hline
\end{tabular}

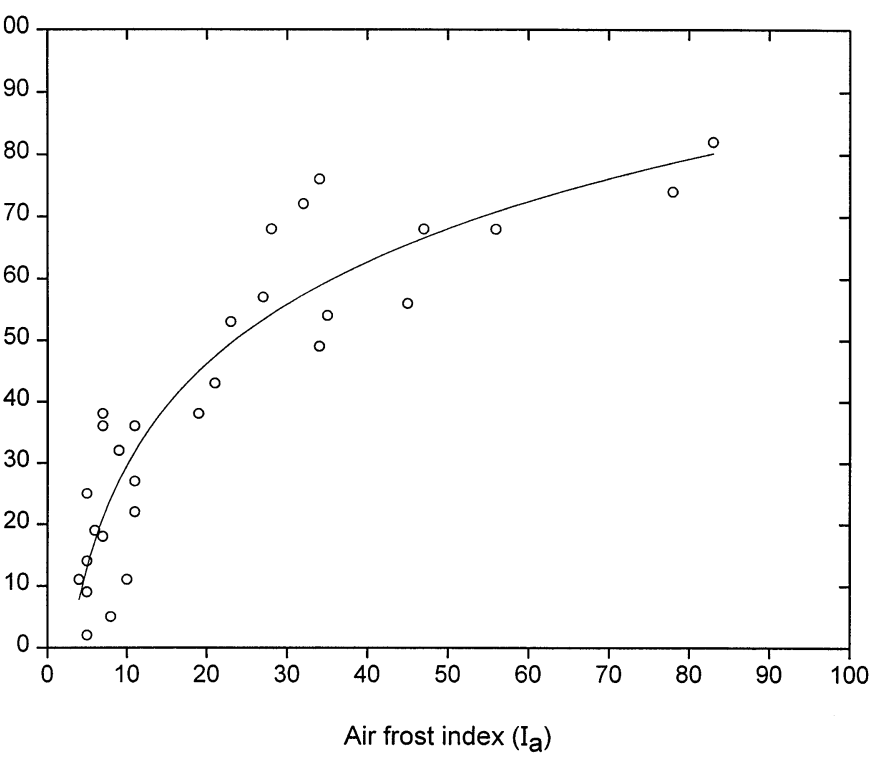

ig. 5. Air frost index, based on frosts in J uly and August, versus the plant mortality after $5 \mathrm{yr}$

stages of plant development are the most susceptible to frost injury. A comparison of the standard deviation values for 1 and 5 yr plant mortality (not shown) indicates that the variability decreases with time for a specific frost intensity, except for moderate frost temperatures, which show increased variability. This highlights the difficulties in determining the impact of frost on the survival of coniferous saplings in the temperature interval -2.5 to $-4.3^{\circ} \mathrm{C}$. Frosts in convex terrain are typically associated with temperatures in this range during the peak of the vegetative period.

An air frost index $\left(I_{a}\right)$ was applied earlier to obtain a quantitative measure of the summer frost intensity. In Fig. 5 the index is plotted against plant mortality $(y)$. The highest correlation between the 2 variables is obtained by a log linear regression: $y=126.6-$ $24.2 \log \left(l_{\mathrm{a}}\right)$. The high correlation coefficient $\left(r^{2}=0.83\right.$, $\mathrm{n}=29$ ) indicates that a large proportion $(83 \%)$ of the variation in mortality can be explained by the summer frost index. This strongly supports the assumption that the frequency and duration of summer temperatures below $-3^{\circ} \mathrm{C}$ are relevant parameters for explaining the distribution of surviving plants in highly elevated complex terrain. According to Fig. 5, a mortality rate of $40 \%$ (mean mortality of the area) occurs at an $\mathrm{I}_{\mathrm{a}}$-value of approximately 20 . This value corresponds to frosts in the temperature interval -4.4 to $-6.2^{\circ} \mathrm{C}$ (see Table 1).

However, there are other causes contributing to variations in plant mortality, with interactions between several different factors being likely to occur. Besides low summer night temperatures, stress variables such as drought, desiccation, soil erosion, erosion from snow and ice crystals, impact from animals and insects, plant 
infections, genetic variability and acclimatisation processes are also of importance. In an attempt to explain the residual that is not accounted for by the frost index, a discussion on some of the mentioned variables is relevant. The residual values in the regression are evaluated in relation to the plant mortality (Fig. 6). The major part of the residuals is randomly distributed between the arbitrary chosen limits of +10 and -10 . However, outliers that show a tendency to cluster occur above and below these limits. Firstly, the highly positive residuals at Sites 4,8 and 11 are discussed mainly with respect to soil frost. Secondly, the clusters in the lower left and the upper right corners of Fig. 6 are discussed in relation to a possible adaptation to spatial differences in low temperatures that may take place after planting.

The plant is subject to desiccation damage when it loses water while assimilating during the day and the uptake of soil water is hindered by soil frost. During the spring and early summer, convex terrain is liable to be exposed to such conditions, as pointed out in Section 4.2 and shown in Table 4. The plant inventory indicates a considerable influence on the mortality rate in such terrain. For example, the average mortality at convex Sites 4, 8 and 11 is twice as high as compared to the mortality at exposed slopes. This cannot be attributed the impact of air frost temperatures alone.

The visible impact on plants exposed to soil frost desiccation is quite similar to that of summer drought. Hanging needles and in severe cases needle discoloration are typical indications of both types of influence. Actually, it is rather the time of the year that indicates the type of impact that takes place. It is obvious that both frost desiccation and severe drought affect the mortality measured after several growing seasons. However, due to the generally harsh temperature climate of this region, soil frost may occur on a yearly basis over a substantial period of time while active growth is in progress, while other types of stress such as fungus attacks and impact from animals occur in a more random way. Thus, we consider that plant desiccation induced by soil frost may explain part of the residual observed in this study.

Plants that are frequently subjected to innocuous low temperatures are believed to show improved resistance to frost (J onsson et al. 1981). Thus, we assume that some degree of adaptation to low temperature can be stimulated throughout the active growth phase, i.e. the susceptible period (Fig. 2). The critical value below which the hardening process is favoured is between +10 and $+3^{\circ} \mathrm{C}$ (J onsson et al. 1981). To obtain a measure of a possible summer hardening in the present study, the sum of hourly observations in the interval 0 to $+5^{\circ} \mathrm{C}$ was calculated for each sampling site. The sums range from 108 to $161 \mathrm{~h}$, a difference greater than $30 \%$. As an example, a comparison of sums and the frost index obtained at slopes of different aspect and elevation was made. Slopes of northern and eastern aspects (e.g. Sites 20, 21 and 22) show temperature sums around $130 \mathrm{~h}$ and index values of 28 to 34 , whereas slopes of western and northwestern aspects (e.g. Sites 10 and 12 ) received sums close to $140 \mathrm{~h}$ and index values of 5 to 10 . The residuals indicate an 'overkill' at the former sites and low mortality rates at the latter sites. This suggests that exposed slopes (Sites 10 and 12) display a higher degree of adaptation in relation to the frost temperatures that they are subjected to.

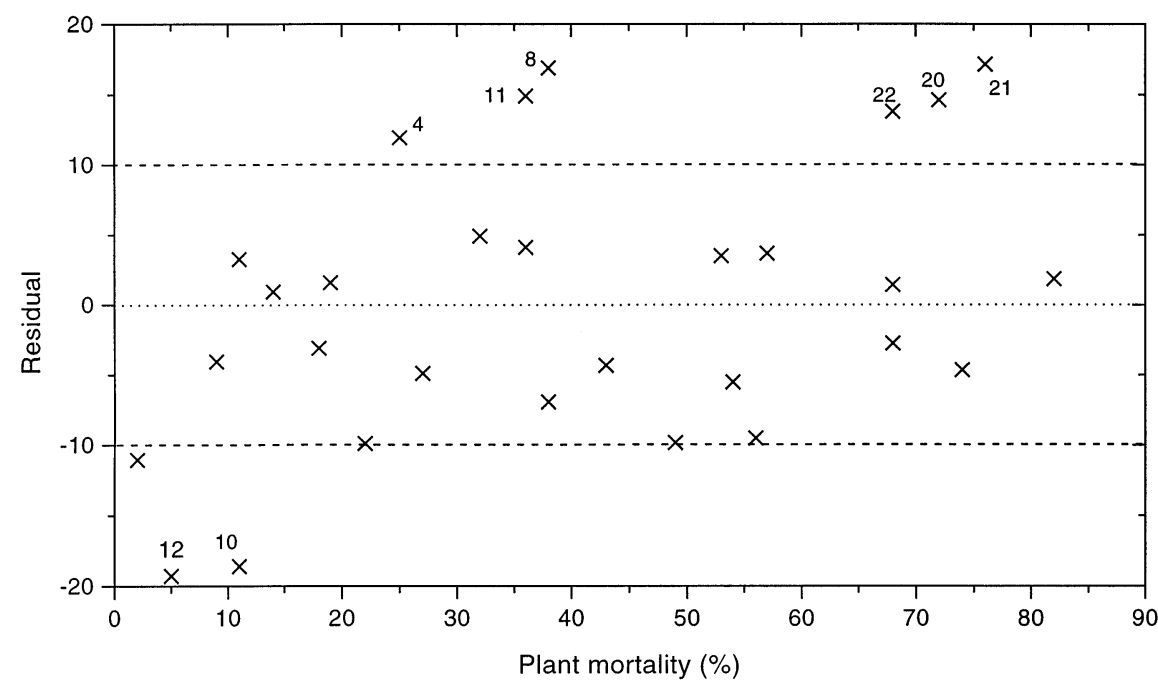

Fig. 6. Relationship between plant mortality and the residuals (deviations in mortality obtained in the regression analysis). The number of certain sites discussed in the text are indicated 


\section{SUMMARY AND CONCLUSIONS}

This work investigates the duration and intensity of low temperatures and their impact on plant injury and mortality in a confined clear-felled area during the peak of the vegetative period. The objective was to identify how terrain features influence the development of summer frost that may lead to the death of plants. Data from 29 stations measuring air temperatures and 4 stations measuring soil temperatures has been utilised to characterise the temperature climate. Two frost indices, one for air temperature and another for soil temperature, were developed to study the relationship between low temperatures and plant mortality. An inventory of planted conifers provided the means to estimate the plant mortality rates for the studied area. Terrain features at each site were classified by a system that includes 4 main types and 2 subtypes.

The conclusions of this study are summarised as follows:

- It was established that the spatial variability and intensity of air frost are the key factors in explaining the range of plant mortality in the study area. Up to $83 \%$ of the variance in the mortality can be accounted for by the frost index alone. In addition, data on soil frost helps explain the relatively high mortality in convex terrain. An analysis of the residuals indicates that possible acclimation processes after planting has taken place are also important.

- It was found that terrain curvature and aspect in relation to azimuth of the sun around sunrise and sunset had a significant impact on the frequency of low temperatures. The intensity and duration of air temperatures below $-3^{\circ} \mathrm{C}$ were highly correlated to the level of plant injury and mortality in the local surroundings of the meteorological stations. Needle discoloration was observed in lower terrain, specifically in areas screened from solar radiation during the afternoon.

- Terrain curvature in relation to the prevailing wind direction during winter is of importance to the snow distribution, giving rise to different times of defrosting in the soil. This difference then influences the level of plant injury and mortality caused by plant desiccation during spring. Plant desiccation effects were found to be similar in appearance to the effects caused by summer drought. In the case of serious desiccation, i.e. repeated exposures, the whole body of the plant was influenced.

- The time of soil defrosting was delayed by nearly $3 \mathrm{wk}$ in unfavourable terrain, i.e. low flat areas and concave terrain, as compared to areas which were highly exposed to wind and incoming radiation. Plant growth in terms of bud burst, shoot elongation and needle elongation was much lower in the former terrain type as compared to the latter.

Editorial responsibility: Chris de Freitas (Contributing Editor), Auckland, New Zealand

\section{LITERATURE CITED}

Ångström A (1974) Climate data for Sweden. Generalstabens litografiska anstalts förlag, Stockholm (in Swedish)

Aronsson A (1979) Variation in frost hardiness of Scots pine (Pinus sylvestris, L.) with season and nutrient status. Swed Univ Agric Sci For Ecol For Soils Rep 35:1-21

Asahina E (1956) The freezing process of plant cell. Contrib Inst Low Temp Sci 10:83-126

Bergman F (1968) The sensitivity to frost for pine and spruce saplings during the vegetative period. Swedish For Soc Publ 2:128-157

Burke MJ , Gusta LV, Quamme HA, Weiser CJ , Li PH (1976) Freezing and injury in plants. Annu Rev Plant Physiol 27: 507-528

Christersson L (1971) Frost damage resulting from ice crystal formation in seedlings of spruce and pine. Physiol Plant 25:273-278

Eiche W (1966) Cold damage and plant mortality in experimental provenance plantations with Scots pine in northern Sweden. Stud For Suec 36:1-219

Fuchinoue $H$ (1982) The winter desiccation damage of tea plant in J apan. In: Li PH, Sakai A (eds) Plant cold hardiness and freezing stress, $\mathrm{Vol} 2$, Mechanisms and crop implications. A cademic Press Inc, p 499-510

Galston AW, Davies PJ , Satter RL (1980) The life of the green plant-control of growth by photoperiod and temperature, 3rd edn. Prentice-Hall International Inc, London, p 308-336

J onsson A, Eriksson G, Dormling I, Ifver J (1981) Studies on frost hardiness of Pinus contorta Dougl. grown in climate chambers. Stud For Suec 157:1-47

Kalma J D, Laughlin GP, Caprio J M, Hamer PJ C (1992) The bioclimatology of frost. Its occurrence, impact and protection. Adv Bioclimatol 2:1-144

Kullman L, Högberg N (1989) Rapid natural decline of upper montane forests in the Swedish Scandes. Arctic 42(3): 217-226

Li PH, Sakai A (eds) (1981) Plant cold hardiness and freezing stress, Vol 2, Part 3. Academic Press, p 199-527

Lindkvist L, Lindqvist S (1997) Spatial and temporal variability of nocturnal summer frost in elevated complex terrain. For Agric Meteorol 87:139-153

Mazur P (1977) The role of intracellular freezing in the death of cells cooled at supraoptimal rates. Cryobiology 14: 251-272

Odin H, Eriksson B, Perttu K (1983) Temperature climate maps for Swedish forestry. Swed Univ Agric Sci For Ecol For Soils Rep 45:1-57

Persson B, Ståhl EG (1990) Survival and yield of Pinus sylvestris, L. as related to provenance transfer and spacing at high altitudes in northern Sweden. Scand J For Res 5: 381-394

Perttu K (1981) Climatic zones regarding the cultivation of Picea abies, L. in Sweden 2. Radiation cooling and frost risk. Swed Univ Agric Sci For Gen Res Uppsala Notes 36:1-25

Sakai A, Larcher W (1987) Frost survival of plants-responses and adaptation to freezing stress. Ecol Stud 62:39-172

Tranquillini W (1979) Physiological ecology of the alpine timberline. Ecol Stud 31:67-81

Venn K, Solheim H (1990) Drought of spruce trees in frozen soils in Norway. Aquilo Ser Bot 29:87-90

Weiser CJ (1970) Cold resistance and injury in woody plants. Science 169:1269-1278

Submitted: March 26, 1997; Accepted: December 21, 1998

Proofs received from author(s): May 10, 1999 